\title{
Genotype X Environment Interaction by AMMI and GGE-Biplot Stability Analysis in Grain Yield for Soybean [(Glycine Max L.) Merrill] in Ethiopia
}

\author{
Mesfin Hailemariam $^{1 *}$, Abush Tesfaye ${ }^{2}$ \\ ${ }^{1}$ Ethiopian Institutes of Agricultural Research, Jimma Agricultural Research \\ ${ }^{2}$ International Institutes of Tropical Agriculture, PMB 5320, Oyo Road 200001, Ibadan, Nigeria \\ *Corresponding Authors: Mesfin Hailemariam, Ethiopian Institutes of Agricultural Research, Jimma \\ Agricultural Research, P.O. Box, 192, Jimma, Ethiopia.

\begin{abstract}
In multi-location trials (MET), test environments need to be identified. properly in order to discriminate between varieties and to be representative of the targeted agro-ecologies. Hence, this experiment was conducted with the objectives was to evaluate the GEI using AMMI and GGE-biplot analysis for grain yield of soybean genotypes and identify stable genotypes in the different soybean agro ecologies of Ethiopia. Twentyfour soybean genotypes were planted at six soybeans agro ecologies of Ethiopia with RCBD in three replications in 2015/2016 cropping season. In addition, the first two IPCAs are significant and accounted for 70.34 form a total of interaction sum squares. Stability measures viz., Additive Main Effects and Multiplicative Interactions (AMMI), AMMI stability value (ASV), and Genotype plus GEI (GGE) bi-plot analysis were used to identify the high yielding and stable genotypes across the testing environments. AMMII biplot showed Pawe is ideal environment; Bako is favorable environment; Asosa average environment; and the rest environments viz., Dimtu, Jimma, and Metu as unfavorable environments. Whereas AMMI-2 biplot analysis genotypes Prichard, Spry, Delsoy 4710 and Croton 3.9 were identified as stable genotypes. Bako and Metu were identified as the most discriminating environments. Mega environments and the best yielding soybean genotypes on each mega environment were revealed by GGE bi-plots analysis model. The genotypes SCS-1 and AGS-7-1 were stable across soybean growing environments and it recommended for mega environment production.
\end{abstract}

Keywords: AMMI, ASV, GGE bi-plot, GEI, IPCA, Stability Analysis, Soybean yield

\section{INTRODUCTION}

Soybean (Glycine max L. Merrill), popularly and often called "miracle bean" as it is extraordinarily rich in protein $(\sim 40 \%)$ and oil ( $20 \%)$. It is the world's foremost provider of high-quality protein and edible oil for both human food and animal feed; in addition, it can improve soil fertility through its capability to fix atmospheric nitrogen (Morsy et al., 1990). It contains well balanced 40\% protein (Lysin rich) and $20 \%$ oil enriched with essential fatty acids.

According to Tesfaye et al. (2018), with its diverse agro-ecological and climatic conditions, Ethiopia is endowed with a very large area of land, where soybean can be suitably produced, especially in rotation with maize. The land suitability analysis shows that soybean is the second among legumes in terms of land area that is moderately and highly suitable for its production in the country, with an estimated 42,067,700 (37.2\%) ha of land (According to EIAR (2017), soybean can be grown in altitudes ranging from 1250 to 2200 meters above sea level (m.a.s.l.); however, it performs well between 1300 and 1700 m.a.s.l. It can also be grown in an area receiving 450 to $1500 \mathrm{~mm}$ annual rainfall; however, to grow very well, and for optimum yields, soybean requires a minimum of $500 \mathrm{~mm}$ annual rainfall. Temperature ranging from $23-25 \mathrm{oC}$ is reported to be optimum for soybean production; however, it performs well at warm temperature and medium relative humidity.

For strong breeding program of any crop such as soybean testing over diverse environment is very important to ensure that the selected genotypes have acceptable performance in variable environments within the target region (Ashraf et al., 2010). Effective interpretation and utilization of data in making 
selection decisions, however, remain a major challenge to researchers. According to Ashraf et al. (2010) there are two major tasks for researcher to determine whether the target region is homogeneous or should be divided into different mega environments; the second is to select superior cultivars for a given megaenvironment on the basis of end product i.e. yields. Varietal adaptability to environmental fluctuations is important for the stabilization of crop production over both the regions and years. An information on GEI leads to successful evaluation of stable genotype, which could be used for general cultivation. Yield is a complex quantitative character and is greatly influenced by environmental fluctuations; hence, the selection for superior genotypes based on yield per se at a single location in a year may be very effective. The study of GEI is crucial for indicating genotypes to each locality (Hamawaki et al., 2015). The recommendation of new soybean cultivars needs desirable characteristics such as pod per plant, plant height at maturity, high protein and oil, among others, together with high grain yield, production stability, and wide adaptation to diverse environments, whose variations can be found in regions where they are indicated (Polizel et al., 2013).

Many investigators described the importance of GEI in stability analysis of soybean (Beaver and Johnson, 1981; Radi et al., 1993; Ablett et al., 1994; Al-Assily et al., 1996 and 2002). The Additive Main Effects and Multiplicative Interaction (AMMI) and GGE biplot models can be powerful tools for effective analysis and interpretation of multi environment data structure in breeding programs (Yan et al. 2000; Ebdon and Gauch 2002; Samonteet al. 2005). In Ethiopia the application of AMMI and site regression model GGE models for explaining and analyzing the performance of genotypes and the tested environments have been very frequent among plant breeder in recent years. Various studies have been conducted in Ethiopia to analyze the effects of GEI on soybean genotypes (Gurmu et al., 2009), Asfaw et al., 2009), but only a few studies use the GGE- bi-plot model.

The magnitude of GEI and investigate the stability of the aimed genotypes using different stability statistics. Therefore, the goal of the present studywas to evaluate the GEI using AMMI and GGE-biplot analysis for grain yield of soybean genotypes andidentify stable soybean genotypes in the different agroecologies for breeding and variety testing purpose.To examine the usefulness of stability model comparing with the two widely used models.

\section{MATERIALS AND METHODS}

The experiments were conducted at six different locations across Ethiopia viz., Dimtu, Jimma, Bako, Metu, Asosa and Pawe. These areas represent the highest potential and the main areas for soybean production in the country, with different edaphic and environmental conditions. The more detailed description biophysical description of the variation explored in the test environment is provided in Table1.

The experiments in all locations were designed in a randomized completely design (RCBD) with three replications per environment under rain feed conditions. Sowing was done manually in rows when necessary. The experimental plot consisted of four ridges, $3 \mathrm{~m}$ long and $60 \mathrm{~cm}$ apart. The other agricultural practices were applied as recommended for each respective location. The soil preparation was done by one plowing and two harrowing right before grooving and fertilizing the soil. At maturity, the two middle ridges of each plot were harvested to determine the seed yield in kilograms per plot $(3.6 \mathrm{~m} 2)$. The experiments were harvested manually when plants reached the R8 stage, according to Fehr and Caviness (1977) scale, in both central lines of each plot, eliminating $0.5 \mathrm{~m}$ of each line edge. Subsequently, it has proceeded the soybean threshing and drying of grains (to $13 \%$ moisture). After drying, for determining the grain yield, the grains from each useful plot had their mass weighed and extrapolated to kgha- 1 . The grain yield data were subjected to AMMI and GGE biplots analysis. All statistical analyses were conducted by PBTools, version 1.4. 2014. Biometrics and Breeding Informatics, PBGB Division, International Rice Research Institute, Los Baños, Laguna.

Table1. Brief description of the experimental environments

\begin{tabular}{|c|c|c|c|c|c|}
\hline No. & Locations & $\begin{array}{c}\text { Altitude } \\
\left(\mathbf{m . a . s .} \mathbf{I}^{*}\right)\end{array}$ & $\begin{array}{c}\text { Geographic Coordinates } \\
(\text { Latitude/ Longitude) }\end{array}$ & $\begin{array}{c}\text { Annual Rain } \\
\text { Fall(mm) }\end{array}$ & $\begin{array}{c}\text { Temperature } \\
\left(\mathbf{0}^{\mathbf{c}}\right) \text { Min. toMax. }\end{array}$ \\
\hline 1. & Asosa (E1) & 1580 & $10^{\circ} 02^{\prime} \mathrm{N} 34^{\circ} 34^{\prime} \mathrm{E}$ & 1130 & $15.9-29$ \\
\hline 2. & Bako (E2) & 1590 & $9^{\circ} 06 \mathrm{~N}^{\circ} 37^{\circ} 09^{\prime} \mathrm{E}$ & 1245 & $9-34.4$ \\
\hline 3. & Jimma (E4) & 1753 & $7^{\circ} 40^{\prime} 9^{\prime \prime} \mathrm{N}, 36^{\circ} 47^{\prime} 6^{\prime \prime} \mathrm{E}$ & 1561 & $18.9-26.8$ \\
\hline
\end{tabular}


Genotype X Environment Interaction by AMMI and GGE-Biplot Stability Analysis in Grain Yield for Soybean [(Glycine Max L.) Merrill] in Ethiopia

\begin{tabular}{|c|c|c|c|c|c|}
\hline 4. & Pawe (E6) & 1120 & $11019^{\prime} \mathrm{N}, 036024^{\prime} \mathrm{E}$ & 1587 & $16.3-32.6$ \\
\hline 5. & Metu (E5) & 1550 & $8^{\circ} 18^{\prime} \mathrm{N}, 35^{\circ} 35^{\prime} \mathrm{E}$ & 1810 & $12.5-28.6$ \\
\hline 6. & Dimtu (E3) & 1640 & $7^{\circ} 55^{\prime} 0^{\prime \prime} \mathrm{N}, 37^{\circ} 20^{\prime} 0^{\prime \prime} \mathrm{E}$ & 1601 & $12.5-26.5$ \\
\hline
\end{tabular}

Table2. A list of soybean cultivars for six environments and their abbreviations that are used for the trials

\begin{tabular}{|c|c|c|c|c|c|c|c|}
\hline $\begin{array}{c}\text { Genotype } \\
\text { Code }\end{array}$ & $\begin{array}{c}\text { Strain Sub- } \\
\text { Designation }\end{array}$ & $\begin{array}{c}\text { Cultivar } \\
\text { Name }\end{array}$ & $\begin{array}{c}\text { Seed } \\
\text { Source* }\end{array}$ & $\begin{array}{c}\text { Genotype } \\
\text { Code }\end{array}$ & $\begin{array}{c}\text { Strain Sub- } \\
\text { Designation }\end{array}$ & $\begin{array}{c}\text { Cultivar } \\
\text { Name }\end{array}$ & $\begin{array}{c}\text { Seed } \\
\text { Source* }\end{array}$ \\
\hline G1 & Mod PI 634193 & 5002T & AON & G13 & Mod PI 559932 & Ks3496 & AON \\
\hline G2 & Mod PI 570668 & Ciaric & AON & G14 & - & Clarck-63k & Released \\
\hline G3 & Mod PI 633970 & Ozark & AON & G15 & Mod PI 533050 & Choska & AON \\
\hline G4 & Mod PI 603953 & Motte & AON & G16 & Mod PI 594669 & Liu yue mang & AON \\
\hline G5 & Mod PI 595081 & Ks4895 & AON & G17 & Mod PI 594675 & Huang dou No-1 & AON \\
\hline G6 & Mod PI & UA4805 & AON & G18 & Mod PI 594675 & Hs93-4118 & AON \\
\hline G7 & Mod PI 560207 & Delsoy 4710 & AON & G19 & Mod PI 614153 & Croton 3.9 & AON \\
\hline G8 & Mod PI 553051 & Spry & AON & G20 & - & SCS-1 & Released \\
\hline G9 & Mod 561702 & Harbar & AON & G21 & Mod PI 639740 & LDOO-3309 & AON \\
\hline G10 & TGX-1892-10F & AFGAT & Released & G22 & Mod PI 612157 & Prichard & AON \\
\hline G11 & Mod PI 594675 & Graham & AON & G23 & Mod PI 633610 & Desha & AON \\
\hline G12 & Mod PI 559932 & Manokin & AON & G24 & Hawassa-04 & AGS-7-1 & Released \\
\hline
\end{tabular}

Sources. EIAR/JARC *AON=Advanced Observation Nursery

\subsection{AMMI and GGE Bi-Plot Analysis}

The results of AMMI and GGE analysis are presented by analysis of variance and biplot graph.

The AMMI model is

$Y_{i j}=\mu+g_{i}+e_{j}+\sum_{k=1}^{x} \lambda_{k} \sigma_{i k} \gamma_{j k}+\varepsilon_{i j r}$

$Y_{i j r=}$ Obserbation of the $r^{t h}$ replicate of the $i^{\text {th }}$ genotype in the environment,

$\mu=$ the overall mean,

$g_{i}=$ main effect of the genotype,

$e_{j}=$ main effect of the $j^{\text {th }}$ environment,

$x=$ matrix $\operatorname{rank}\{g e\}_{i j}$,

$\lambda_{\mathrm{k}}=$ the singular value for principal component $k$,

$\sigma_{i k}=$ the eigen vector score for genotype $\mathrm{i}$ and component $\mathrm{k}$,

$\gamma_{j k}=$ the eigen vector score for environment $j$ and componenet $k$,

\subsubsection{Ammi Stability Value (Asv)}

Since AMMI does not provide a quantitative measurement, it is necessary to quantify and rank genotypes and based on their yield (Purchase, 1997). AMMI Stability Value (ASV), length of genotype and environment markers of the origin in a two-dimensional plot of IPCA1 sores againstIPCA2 scores was calculated according to Purchase et al. (1997) as:

$$
A S V=\sqrt{\left.\left[\frac{\text { IPCA1 Sum Squares }}{\text { IPCA2 Sum Squares }} \text { IPCA1 Score }\right)\right]^{2}+[\text { IPCA2 Score }]^{2}}
$$

Where: IPCA1 = interaction principal component axis 1 ; IPCA2 = interaction principal component, axis 2. According to Purchase (1997) genotypes with lower values of the ASV are considered to be more stable.

The GGE model is 
$Y_{i j}=\mu+e_{j}+\sum_{k=1}^{x} \lambda_{k} \sigma_{i k} \gamma_{j k}+\varepsilon_{i j r}$

$Y_{i j r}=$ Obserbation of the $r^{t h}$ replicate of the $i^{\text {th }}$ genotype in the environment, $\mu=$ the overall mean,

$\lambda_{\mathrm{k}}=$ the singular value for principal component $k$,

$e_{j=}$ The mean effect of the $j^{\text {th }}$ environment,

$x=$ matrix $\operatorname{rank}\{g g e\}_{i j}$ when $\{g g e\}_{i j}=g_{i}+g e_{i j}$

$\sigma_{i k}=$ the eigen vector score for genotype $i$ and componenet $k, \gamma_{j k=}$ the eigenvector score for environment $j$ and component $k$, and $\varepsilon_{i j r}=$ the error for the genotype $i$ and environment $j$ and replicate $r$.

\section{RESULTS AND DISCUSSION}

\subsection{GGE Biplot Analysis}

\subsubsection{Performance of Genotypes in a Specific Environment}

Environment's vector is $\left\langle 90^{\circ}\right.$; it is lower than average, if the angle is $>90^{\circ}$; and it is near average, if the angle is about $90^{\circ}$. In this case, Choska was below average in nearly all environments except E3 and E4 whereas Choska was above average in all environments except in E5 (Fig.1).

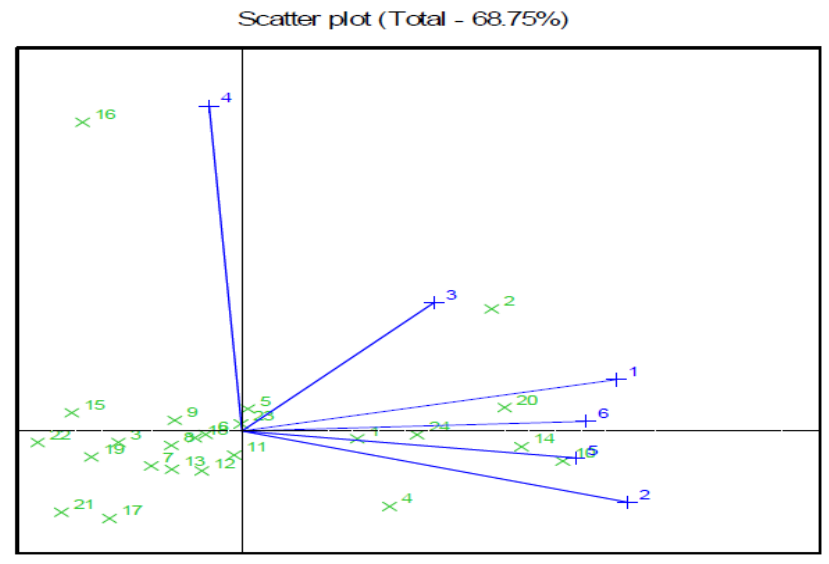

Performance of each genotype in each environment

Figure1. The GGE biplot showing the performance of each genotype in each environment.

\subsubsection{The Which-Won-where Pattern}

According to Yan et al., 2002 the polygon view of GGE biplot indicates the best genotypes in each environment and group of environments. In this situation, the polygon is formed by connecting the signs of the genotypes that are farthest away from the biplot origin, such that all other genotypes are contained in the polygon. In this case, the polygon connects all the farthest genotypes and perpendicular lines divide the polygon into sectors. Sectors help to visualize the mega-environments. This means that winning genotypes for each sector are placed at the vertex. The pattern on the environment in the above biplot suggests that the existence of three different mega-environments (Fig.2). But this pattern may not be repeatable across years (Yan et al. 2000). To confirm the repeatability of the mega-environment result, there need to be multiyear data (Yan et al. 2005).For studying the possible existence of different megaenvironments in a region, visualization of "which -won-where" Pattern of the Meta environment trial is important as described by Yan et al, 2000,2001). The vertex genotypes in this investigation were Hang dou No-1 (G17), AFGAT (G10), SCS-1 (G20), 5002T (G1), Choska (G15) and Princhard (G22). This means that the vertex genotypes for each sector are the one that gave the highest yield for the environments that fall within that sector. Besides, it is evident from the GGE biplot in fig.2 that environmental groupings, which suggests the possible existence of different mega environments. Thus, 
based on the biplot analysis of six environments of the data. The highest yielding in the environment in five and two are AFGAT (G10). And in environment six and one AGS-7-1 (G24). The other vertex genotypes are Choska (G15), Prichard (G22) and Hang douNo-1 (G17) are poor performing in all the six environments.

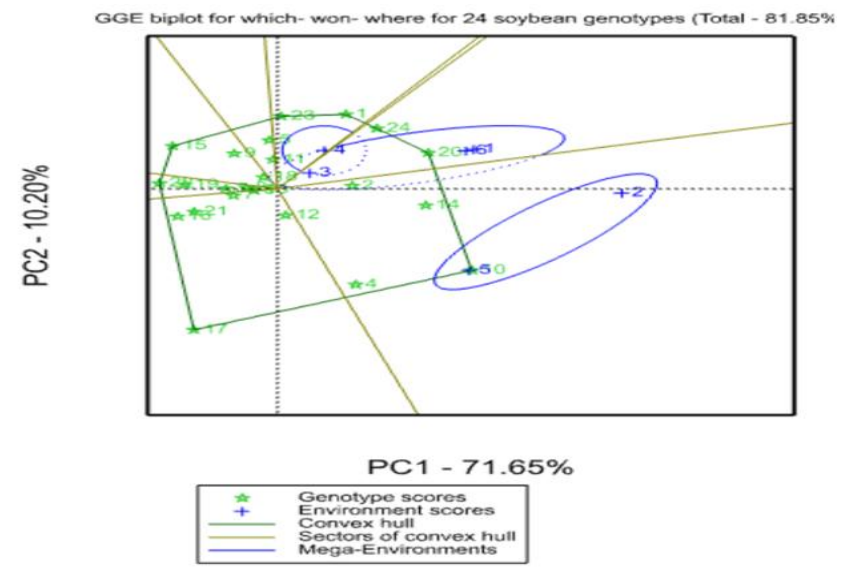

Which genotype won where?

Figure2. "Which-won-where" or "Which is best for what" pattern of GGE biplot based on 24 soybean genotypes evaluated in six soybean agro-ecologies of Ethiopia.

\subsubsection{Ideal Test Environments for Selecting Generally Adapted Genotypes}

Within a single mega-environment, the ideal test environment should be most discriminating (informative) and also most representative of the target environment. Figure 3 defines an "ideal test environment", which is the center of the concentric circles. It is a point on the Average Environment Coordinate in the positive direction ("most representative") with a distance to the biplot origin equal to the longest vector of all environments ("most informative"). E2 (Bako) is closest to this point and is, therefore, best, whereas E5 and E4 were poorest for selecting cultivars adapted to the whole region. Note that additional years are required to confirm that a specific test location is "ideal".

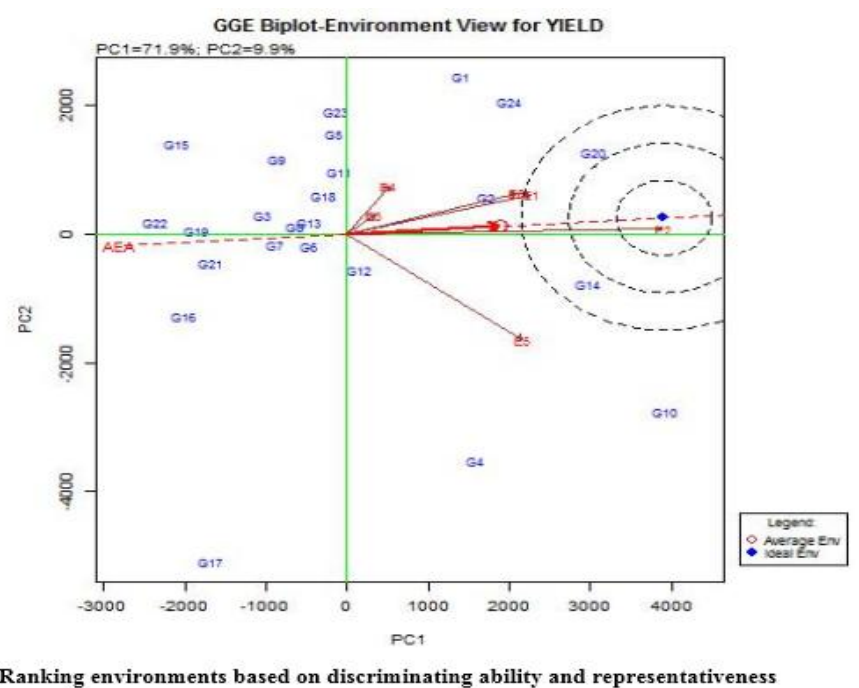

Figure3.The discrimination and representatives view of the GGE biplot to rank test environments relative to the ideal environments.

\subsubsection{Ranking of Genotypes based on Relative to the Ideal Genotypes}

The ideal genotypes (the center of concentric circles) to be a point on AEA in the positive direction and has a vector length equals to the longest vector of the genotypes on the positive side of the AEA ("highest 
mean performance"). As a result, genotypes located closer to the "ideal genotypes" are more desirable than the others. Hence, the GGE biplots (Fig.4) shows that G10 is an ideal genotype, with other genotypes like G20 and G14 are desirable genotypes as they are closer to the ideal genotype on the bi-plot.

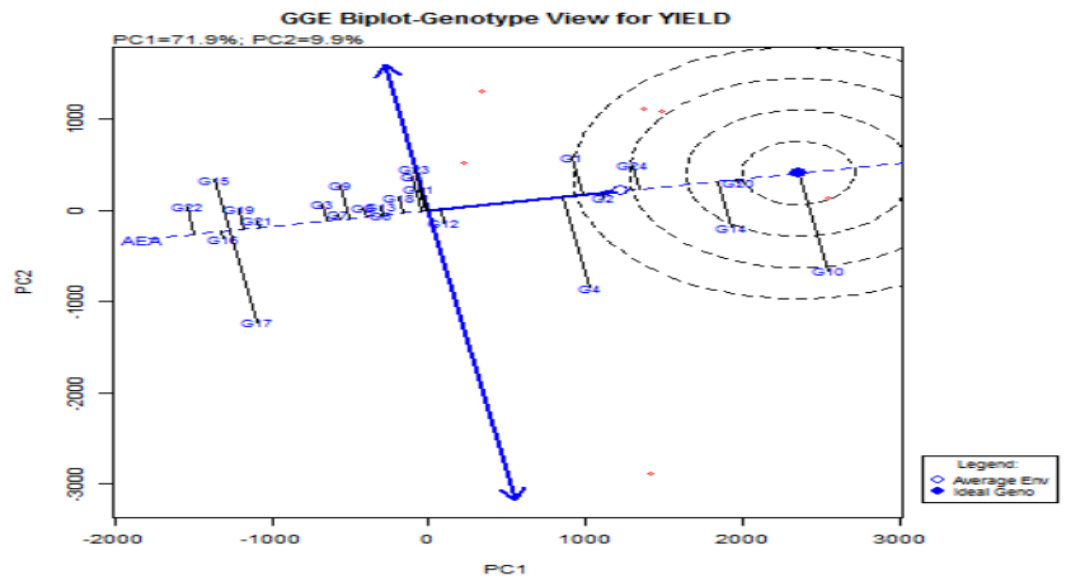

Ranking genotypes based on both mean and stability

Figure4.The average-environment coordination (AEC) view to rank genotypes relative to an ideal genotype.

\subsubsection{Relationships Among Test Environments}

As displayed in Fig.5 the lines that connect the environments to the biplot origin are called environment vectors, and the length of environmental vectors is proportional to their standard deviation, which measures the discriminating ability of the environments. At the same time the angle between the vectors of two environments is related to the correlation coefficient between them. According to Kroonenberg (1995) and Yan (2002) the cosine angle between the vectors of two environments approximates the correlation coefficient between them. Based on the angles of environment vectors, the six sites are grouped into three groups. Accordingly, group one includes Jimma and Dimtu; group two Asosa and Pawe, and group three Bako and Metu.

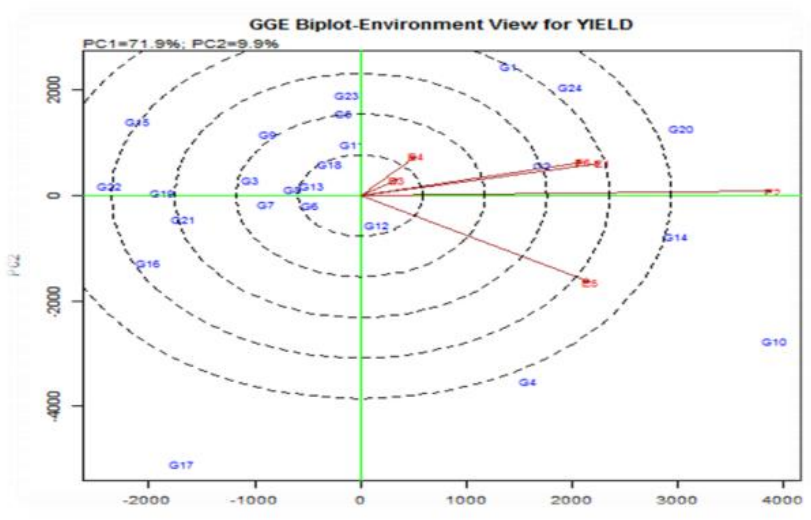

Discrimitiveness vs. reperesentativeness of test environments

Figure5. GGE biplots based on environment focused scaling for environments to show relationship among test environments in discriminating genotypes.

\subsubsection{Comparison Among all Genotypes}

The is the distance between two genotypes approximates the Euclidean distance between them, which is a measure of the overall dissimilarity between them (Yan et al., 2006). In this case, Ciaric (G2) and SCS-1 (G20) are quite similar, whereas Hang douNo-1 (G17) and AFGAT (G10) are very different. This implies that the dissimilarity is because of the variation in mean yield and or interaction with the environments. In 
addition, the biplot origin represents a "virtual" genotype that assumes an average value in each of the environment. This "average" genotype has zero contributions to both G and GE (Yan et al.,2006) and inversely genotypes with larger vectors have large contributions to either G or GE or both. In this case Manokin (G12) and other genotypes in the smaller concentric circle are the average genotypes.

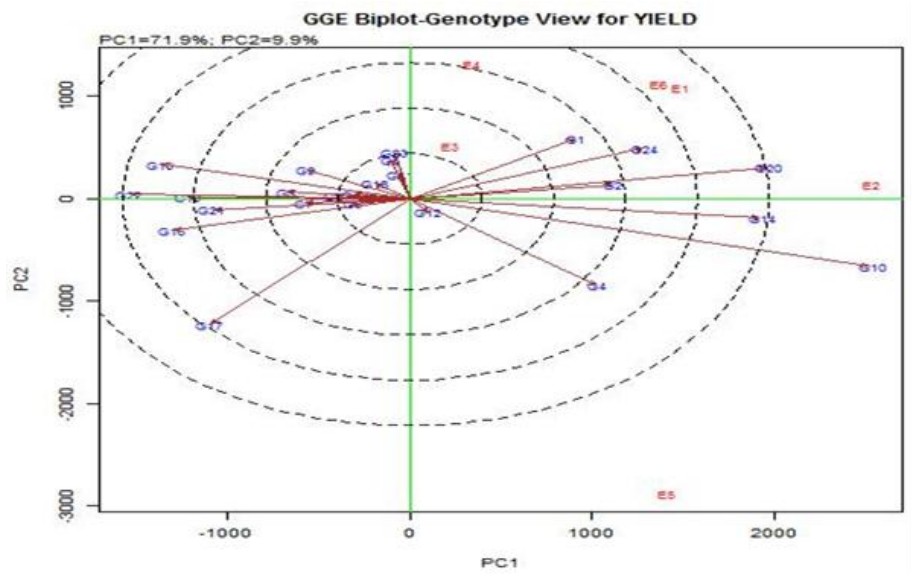

Similarity among genotypes

Figure6. The genotype vector views to show similarity among genotypes in their performances in their individual environments.

\subsection{Additive Main Effects and Multiplicative Interactions (AMMI)}

According to AMMI analysis for grain yield, the first two interaction principle components have taken the largest portions (70.34\%) of the interaction sum squares with $50.3 \%$ and 20.04 and 27 and 25 degree of freedom respectively (Table 3). The AMMI model integrates the analysis of variance into a unified approach (Gauch, 1988; Gauch and Zobel, 1996). IPCA scores of genotypes in the analysis are an indication of the stability of a genotype over the environments (Guach and Zobel, 1997).

The combined analysis of variance (ANOVA) of twenty-four genotypes at six locations according to AMMI model 2 is shown in Table 3 . The ANOVA showed that a highly significant $(\mathrm{P} \leq 0.01)$ between environments, genotypes and genotype by environment interaction (GEI) for grain yield. The IPCA 1 axis was very highly significant $(\mathrm{P} \leq 0.001)$ for grain yield, while IPCA 2 axis was significant $(\mathrm{P} \leq .0 .05)$. IPCA 1 and IPCA 2 axes explained $50.30 \%$ and $20.04 \%$ of the total GEI, while the remaining $29.66 \%$ were shared between other IPCA's. This showed that AMMI model 2 was best suited because gave for this data set.

Table3. Analysis of Variance of AMMI model for grain yield $\left(\mathrm{Kg} \mathrm{ha}^{-1}\right)$ of 24 soybean genotypes.

\begin{tabular}{|c|c|c|c|c|c|c|}
\hline Source of & & & & \multicolumn{2}{|c|}{ Sum Square Explained } & GEI \\
\cline { 5 - 6 } Variation & DF & SS & MS & \% TT & \%GEI & \\
Cumulative(\%)
\end{tabular}

$* * * \mathrm{P}<0.001 ; * \mathrm{P}<0.05$; IPCA=Interaction Principle components axis term 1 to $2 ; \mathrm{DF}=$ Degree of freedom; SS=Sum of Squares; MS=Mean Square, $=$ Coefficient of variation; $\mathrm{R}=$ Coefficient determination . 
The AMMI analysis permits the estimation of interaction effects of genotype in each and it helps identify the genotypes best suited for specific environments. Selection of genotypes can be obtained with the aid of biplot analysis.

The AMMI model summarizes patterns and relationships of genotypes and environments. Fig 7(a). Shows the AMMI model 2 biplot of grain yield for six locations. The IPCA2 score plays a major role in GEI (Purchase, 1997), so they should be plotted against the IPCA1 scores to further explore the adaptations. Genotypes closer to zero or center of the figure are more stable Fig 7(a) indicates the IPCA1 and IPCA2 score for grain yield to further explore further adaptations. The further away from zero the IPCA score for the environments is the more interaction the environment has with the genotypes, thus making difficult to choose genotypes for that environment.

In AMMI biplot 1 showing main effects means on the abscissa and principal component (IPCA) values as the ordinates, genotypes (environments) that appear almost on a perpendicular line have similar means and those that fall on the almost horizontal line have similar interaction patterns. Genotypes that group together have similar adaptation while environments which group together influences the genotypes in the same way. Genotypes (environments) with large IPCA1 scores (either positive or negative) have high interactions whereas genotypes (environments) with IPCA1 score near zero have small interactions.

Genotypes having a zero IPCA1 score are less influenced by the environments and adapted to all environments. Since IPCA1 scores of varieties Graham (G11), LD00-3309 (G21), Hs93-4118 (G18) ks3496 (G13) and Spry(G8) were close to zero, they were most stable genotypes that across these environments (Figure 7(a)). However, the mean yield of genotype Spry (G8) was higher than genotype the remaining genotypes, hence it is more preferable since it had a mean yield above average, but the rest four genotypes have mean below average. In summary, a stable variety might not be the highest yielding. These results are in line with Asfaw et al. (2009).

The environments having a small score had small interaction effects indicating all genotypes performed well in these locations. Pawe (E6) was relatively close to zero than other locations, it was more stable. But its mean yield is third compared with the rest locations; it might not be the best location with respect to yield. Generally, genotypes and environments with IPCA1 scores of the same sign produce positive interaction effects, thus higher yield of the genotype at that particular location, whereas combination of the IPCA 1 scores of the opposite sign produce specific negative interactions. A genotype showing high positive interaction in an environment has the ability to exploit the agroecological and agro-management conditions of the specific environment and is therefore best suited to that environment. In this case, Choska (G15), Prichard (G22), Liu yuemang (G16), and Croton 3.9 (G19) are suited for E4 (Jimma). While SCS-1(G20) is suited for E1 (Asosa).

AMM 2 biplot presents the spatial pattern of the first two IPC axes of the interaction effect corresponding to the genotypes and helps in the visual interpretation of the GEI pattern and identify genotypes or environments that exhibit low, medium, or high level of interaction effects (Sharma et al., 1998). IPCA1 and IPCA2 of grain yield accounted for $50.30 \%$ and $20.04 \%$ of interactionrespectively. The stability of a genotype or an environment is determined by the end point of its vector from the origin $(0,0)$. Genotypes near the origin are non-sensitive to environmental interactive forces, hence may be considered stable ones and those distant from origin are sensitive and have large interactions. Genotypes Prichard, Spry, Delsoy 4710, Croton 3.9, and Manokin were closer to the origin than any of other genotypes, hence they are most stable (Fig.7b). In AMMI 2 biplot, the environment scores are joined to the origin by the site lines. Environments with short spokes (length of arrow lines) do not exert strong interactive forces. Those with long spokes (length of arrow lines) exert strong interaction. Metu (E5) and Bako (E2) having longer spokes exert high interaction while Asosa (E1), Pawe (E6), Dimtu (E3) and Jimma (E4) having shorter spokes produce a relative weak interaction.

The graph space Fig.7 (b) are divided into IV quadrant from lower yielding environments in quadrant I and IV to high yielding in quadrants II and III. In Addition, quadrant II considered as ideal environment. So, from the graph in Fig.7b, Asosa (E1), Bako (E2) and Pawe (E6), which is in quadrant II, are ideal 
environments, while quadrant II characterizes in high yielding environment with unstable genotypes, in this quadrant Metu (E5) is found. Similarly, in quadrant I characterized, stable genotypes and low yielding and in contrast quadrant IV unstable genotypes with the low yielding environment.
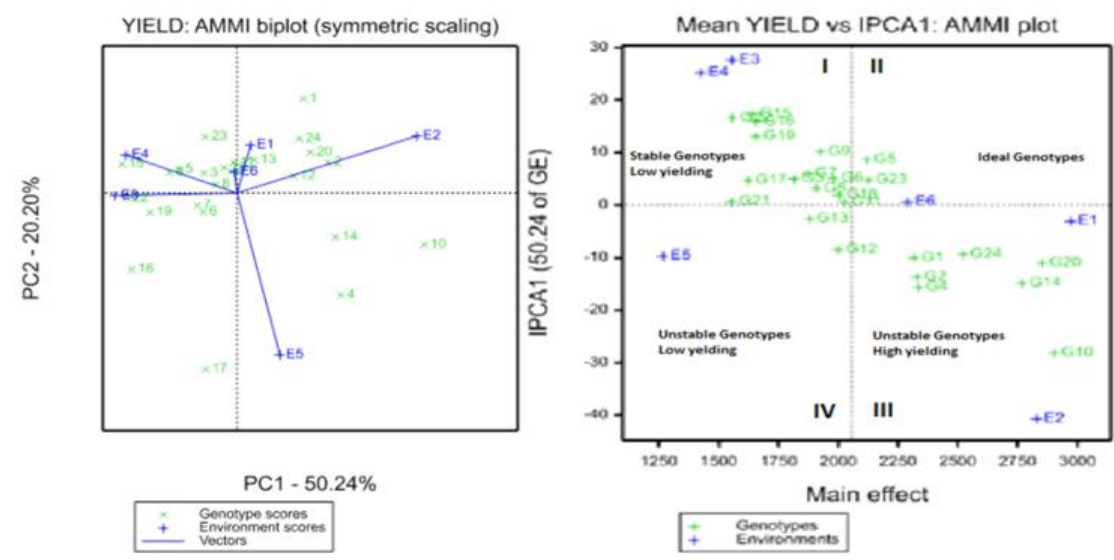

Figure7(a).Biplots principle component analysis (PCA) vs mean yield $\left(K g \mathrm{ha}^{-1}\right)$ for twenty-four soybean genotypes grown in six environments in 2015/2016 cropping season and(b).Biplots of principle components analysis (PCA) axis 2 vs axis 1 for yield.

\subsubsection{AMMI Stability Value (ASV)}

The ASV measure was proposed by Purchase et al. (2000) to cope up the fact that the AMMI model does not make a provision for a quantitative stability measure. In this method, as described by Purchase (1997) was calculated for each genotype. Depending on this method, genotype with least ASV score is the stable, accordingly, genotype LD00-3309 (G21) followed by Graham (G11) and Spry (G8) in third place were the most stable respectively. While genotypes AFGAT (G10), Motte (G4), Hang dou No-1(G17), Liu yuemang (G16) and Choska (G15) were undesirable. This result also similar to the three genotypes grain mean yield rank. This method illustrated in Table 4 Shows the ASV for 24 genotypes compared with mean grain yield.

The greater the IPCA scores (Negative or Positive), the more specifically adapted a genotype is to certain environment. The closer the IPCA scores to zero, the more stable the genotype over the tested locations. The further away from zero the IPCA score for the environments is the more interaction the environment has with the genotypes, thus making difficult to choose genotypes for that environment.

\subsubsection{Yield Stability Index (YSI)}

Yield stability index incorporates both mean yield and stability in a single criterion. The minimum values of YSI desirable genotypes with high mean yield and stability.

Table4. The first and second IPCA, Grain Mean yield and various yield_stability statistics investigated in soybean genotypes over rain feed conditions.

\begin{tabular}{|c|c|c|c|c|c|c|c|c|}
\hline Genot.ID & Genotypes & GM$\left(\right.$ Kgha $\left.^{-1}\right)$ & Rank & IPCA1 & IPCA2 & ASV & Rank & YSI \\
\hline G1 & 5002T & 2319 & 7 & -10.71 & 14.67 & 22.44 & 16 & 23 \\
\hline G2 & Ciaric & 2385 & 5 & -14.42 & 6.57 & 23.78 & 17 & 22 \\
\hline G3 & Ozark & 1815 & 18 & 5.30 & 3.72 & 9.18 & 7 & 25 \\
\hline G4 & Motte & 2337 & 6 & -15.66 & -17.05 & 30.10 & 23 & 29 \\
\hline G5 & ks4895 & 2121 & 8 & 8.63 & 3.88 & 14.22 & 11 & 19 \\
\hline G6 & UA4805 & 1981 & 13 & 4.99 & -3.08 & 8.49 & 6 & 19 \\
\hline G7 & Delsoy 4710 & 1871 & 17 & 6.25 & -1.72 & 10.05 & 8 & 25 \\
\hline G8 & Spry & 1909 & 15 & 3.24 & 1.62 & 5.39 & 3 & 18 \\
\hline G9 & Harbar & 1926 & 14 & 10.07 & 3.46 & 16.33 & 12 & 26 \\
\hline G10 & AFGAT & 2903 & 1 & -28.11 & -8.55 & 45.35 & 24 & 25 \\
\hline G11 & Graham & 2027 & 10 & 0.36 & 4.80 & 4.83 & 2 & 12 \\
\hline G12 & Manokin & 2000 & 12 & -8.15 & 3.02 & 13.26 & 10 & 22 \\
\hline G13 & ks3496 & 1880 & 16 & -2.55 & 5.59 & 6.90 & 5 & 21 \\
\hline
\end{tabular}


Genotype X Environment Interaction by AMMI and GGE-Biplot Stability Analysis in Grain Yield for Soybean [(Glycine Max L.) Merrill] in Ethiopia

\begin{tabular}{|c|c|c|c|c|c|c|c|c|}
\hline G14 & Clarck-63k & 2770 & 3 & -14.54 & -7.84 & 24.33 & 18 & 21 \\
\hline G15 & Choska & 1641 & 21 & 16.97 & 5.00 & 27.35 & 20 & 41 \\
\hline G16 & Liu yuemang & 1656 & 19 & 15.77 & -12.34 & 27.87 & 21 & 40 \\
\hline G17 & Hang dou No-1 & 1623 & 22 & 5.04 & -28.54 & 29.63 & 22 & 44 \\
\hline G18 & Hs93-4118 & 2003 & 11 & 2.17 & 4.44 & 5.61 & 4 & 15 \\
\hline G19 & Croton 3.9 & 1656 & 20 & 13.20 & -3.02 & 21.13 & 15 & 35 \\
\hline G20 & SCS-1 & 2853 & 2 & -11.07 & 6.55 & 18.72 & 14 & 16 \\
\hline G21 & LD00-3309 & 1554 & 24 & 0.92 & 3.91 & 4.18 & 1 & 25 \\
\hline G22 & Princhard & 1558 & 23 & 16.52 & -0.36 & 26.18 & 19 & 42 \\
\hline G23 & Desha & 2072 & 9 & 4.92 & 7.04 & 10.51 & 9 & 18 \\
\hline G24 & AGS-7-1 & 2522 & 4 & -9.16 & 8.20 & 16.67 & 13 & 17 \\
\hline
\end{tabular}

NB: $G M=$ Grain Mean; IPCAl= interaction principle component one; $I P C A 1=$ interaction principle component two; YSI=Yield Stability Index.

\subsubsection{AMMI Selections for the Highest Four Yielding Cultivars Across Six Environments}

The AMMI model selected four best genotypes for in each environment and illustrated in Table 5.

The genotype that appeared in the top four environments in at least six environments was Clarck-63k, which is followed by; SCS-1(five env.), AFGAT (four), AGS-7-1(four), Ks4895(two). The other cultivar, Hang douNo-1, Ciaric and Motte appeared only once.

Table5.Ranking of four AMMI selections per environment for grain yield $\left(\mathrm{Kg} \mathrm{ha}^{-1}\right)$.

\begin{tabular}{|c|c|c|c|c|c|c|c|}
\hline & & \multirow{2}{*}{$\begin{array}{c}\text { Mean } \\
\text { Number }\end{array}$} & \multirow{2}{*}{$\begin{array}{l}\text { IPCA } \\
\text { Environment }\end{array}$} & Kg ha $\left.^{-1}\right)$ & Score & \multicolumn{4}{|c|}{ Genotype Ranking $^{\text {rd }}$} & 1st & $2^{\text {nd }}$ & $\mathbf{3}^{\text {th }}$ \\
\hline 3 & Dimtu & 1557 & 28.09 & G20 & G5 & G14 & G24 \\
\hline 4 & Jima & 1426 & 25.46 & G20 & G5 & G24 & G14 \\
\hline 6 & Pawe & 2291 & 1.07 & G20 & G10 & G14 & G24 \\
\hline 1 & Asosa & 2973 & -5.28 & G20 & G10 & G14 & G24 \\
\hline 5 & Metu & 1268 & -9.13 & G10 & G14 & G4 & G17 \\
\hline 2 & Bako & 2830 & -40.22 & G10 & G20 & G14 & G2 \\
\hline
\end{tabular}

\section{CONCLUSION}

From the present investigation, it is concluded that multiple methods were employed to analyze stability. Those methods provided a good understanding of the adaptation level of soybean genotypes across a diverse range of environments. The AMMI and GGE biplot analysis permitted estimation of interaction effect of a genotype in each environment and it helped to identify genotypes best suited for specific environments. GGE biplot analysis showed that the polygon view of a biplot is the best way to visualize the interaction models between genotypes and environments. The polygon views of the GGE biplot pointed out that there existed three possible mega environments. The first mega environment consisted of two environments (E3 and E4), the second mega environment consisted of two environments (E1 and E1) and the third with two environments (E5 and E2). In addition, the discriminating power vs. representativeness view of the GGE biplot has been an effective tool for test environments evaluation. Environment E2 were the most discriminating for grain yield of the tested soybean genotypes, whereas E5 and E4 were poorest for selecting cultivars adapted to the whole region. The results indicated that GGE and AMMI biplot are facilitated visual comparison and informative methods to detect genotypes stability and in the preferential genotypes recommendations.

\section{ACKNOWLEDGEMENT}

The author would like to thank to all persons who participated in the field research. This research was supported by the Ethiopian Institutes of Agricultural Research (EIAR) and Soybean Innovation lab (SIL).

\section{REFERENCES}

[1] Acquaah, G., 2007.Principles of plant genetics and breeding. Blackwell Publishing, Malden .569p

[2] Adie, M.M., Krisnawati, A. and Gatut-Wahyu, A.S., 2014.Assessment of Genotypex Environment Interactions for Black Soybean Yield using Ammi and GGE Biplot. International Journal of Agriculture Innovations and Research,2(5): 673-678. 
[3] Allard, R. W. and Bradshaw, A. D. 1964. Implications of genotype-environment interactions in applied plant breeding. Crop Sci. 4: 503-508

[4] Akram, R.M., Fares, W.M., EL-GARHY, A.M. and Ashrie, A.A.M.,2012. Regression Models vs. Variance Measures as Stability Parameters of Some Soybean Genotypes. Bangladesh Journal of Agricultural Research.

[5] Amira, J.O., Ojo, D.K., Ariyo, O.J., Oduwaye, O.A. and Ayo-Vaughan, M.A., 2013. Relative discriminating powers of GGE and AMMI models in the selection of tropical soybean genotypes. African Crop Science Journal,21(1):67-73.

[6] Annicchiarico, P. (2002). Defining adaptation strategies and yield stability targets in breeding programmes. In Kang, M.S. (Ed.) Quantitative genetics, genomics and plant breeding, Wallingford, UK, CABI:365-383.

[7] Annicchiarico, P. 2002. Genotype $\times$ Environment Interactions: Challenges and Opportunities

[8] Annicchiarico, P., 2002. 24 Defining Adaptation Strategies and Yield-stability Targets in Breeding Programmes. Quantitative genetics, genomics, and plant breeding, p.365.

[9] Asfaw, A., Alemayehu, F., Gurum, F. and Atnaf,M. 2009. AMMI and SREG GGE biplot analysis for matching varieties onto soybean production environments in Ethiopia. Scientific Research and Essay 4(11):1322-1330.

[10] Atnaf, M., Kidane, S., Abadi, S. and Fisha, Z., 2013. GGE biplots to analyze soybean multi-environment yield trial data in north Western Ethiopia. Journal of Plant Breeding and Crop Science, 5(12):245-254.

[11] Crossa, J., 1990.Statistical analyses of multilocation trials. Advances in agronomy, 44:55-85.

[12] 12. Crossa, J., 1990.Statistical analyses of Multilocation trials.pp.55-85. In N.C.Brady(eds).

[13] Morsy, A.R., Fares, W.M., Ragheb, S.B. and Ibrahim, M.A., 2015. Stability analysis of some soybean genotypes using a simplified statistical model. J. Plant Prod. Mansoura Univ, 6(12), pp.1975-1990.

[14] EIAR, 2017. Pulses Research Strategy: 2016-2030. Ethiopian Institute of Agricultural Research, Addis Ababa, Ethiopia.

[15] Fehr WR, Caviness CE (1977). Stages of soybean development. Special report - 80, Iowa State University of Science and Technology, Ames

[16] Gurmu, F., Mohammed, H. and Alawa, G., 2009. Genotype x environment interactions and stability of soybean for grain yield and nutrition quality. African Crop Science Journal, 17(2):87-99.

[17] Hamawaki RL, Hamawaki OT, Nogueira APO, Hamawaki CDL, et al. (2015). Adaptability and Stability Analysis of Soybean Genotypes Using Toler and Centroid Methods. Am J Plant Sci. 6: 1509-1518. https://doi.org/10.4236/ajps.2015.69150

[18] Kanouni, H., Farayedi, Y., Saeid, A. and Sabaghpour, S.H., 2015.Stability Analyses for Seed Yield of Chickpea (Cicer arietinum L.) Genotypes in the Western Cold Zone of Iran. Journal of Agricultural Science, 7(5):219.

[19] Karasawa, K. 1952 Crossing Experiments with Glycine soja and G. gracilis. Genetica 26:357-358.

[20] Kaya, Y. and Ozer, E., 2014.Parametric stability analyses of multi-environment yield trials in Triticale (xTriticosecale Wittmack). Genetika,46(3): 705-718.

[21] Masindeni, D.R., 2006.Evaluation of bambara groundnut (Vigna subterranea) for yield stability and yield related characteristics. An Msc thesis presented to University of the Free State, 103p.

[22] PBTools (2014) Biometrics and Breeding Informatics, Version 1.4. PBGB Division. International Rice Research Institute, Los Banos, Laguna.

[23] Purchase, J.L. 1997. Parametric analysis to describe genotype by environment interaction and stability in winter wheat. PhD. thesis. Department of Agronomy, Faculty of Agriculture, University of the Orange Free State, Bloemfonten, South Africa.

[24] Purchase, J.L., Hatting, H. and Van Deventer, C.S., 2000. Genotypex environment interaction of winter wheat (Triticum aestivum L.) in South Africa: II. Stability analysis of yield performance. South African Journal of Plant and Soil, 17(3):101-107.

[25] SAS Institute Inc. (2004). SAS software release. SAS Institute, Inc., Cary, NC, USA.

[26] Tukamuhabwa, P., Rubaihayo, P. and Dashiell, K.E., 2002.Genetic components of pod shattering in soybean. Euphytica, 125(1):29-34.

[27] VSN. 2011. GenStat for Windows: fourteenth edition. Release 16.1.VSN International, Ltd, Hemel Hempstead, United Kingdom.

International Journal of Forestry and Horticulture (IJFH)

Page $\mid 20$ 
[28] Yan, W. and Tinker, N.A., 2006. Biplot analysis of multi-environment trial data: Principles and applications. Canadian Journal of Plant Science, 86(3):623-645.

[29] Yan, W. and Wu, h., 2008.Application of GGE biplot Analysis to Evaluate Genotype (G), Environment (E), and G×E interaction on pinus radiata: A case study. New Zealand Journal of Forestry Science, 38(1):132-142.

[30] Yan, W., Cornelius, P.L., Crossa, J. and Hunt, L.A., 2001.Two types of GGE biplots for analyzing multienvironment trial data. Crop Science, 41(3):656-663.

[31] Yan, W., Hunt, L.A., Sheng, Q. and Szlavnics, Z., 2000. Cultivar evaluation and mega-environment investigation based on the GGE biplot. Crop Science,40(3):597-605.

[32] Yan, W. and Frégeau-Reid, J., 2018. Genotype by Yield* Trait (GYT) Biplot: a novel approach for genotype selection based on multiple traits. Scientific reports, 8(1), p.8242.

[33] Zelalem, T., 2011. Statistical Analysis of Genotype by Environment Interactions and Grain Yield stability in bread wheat using ANOVA and AMMI models. An MSc Thesis Presented to the School of Graduate Studies of Addis Ababa University,86p.

[34] Zobel, R.W., Wright, M.J. and Gauch, H.G., 1988. Statistical analysis of a yield trial. Agronomy Journal,80(388-399.

[35] Multi-environment response in seed yield of soybean [Glycine max (1.) Merrill], genotypes through GGE biplot technique

Citation: Mesfin Hailemariam \& Abush Tesfaye " Genotype X Environment Interaction by AMMI and GGEBiplot Stability Analysis in Grain Yield for Soybean [(Glycine Max L.) Merrill] in Ethiopia", International Journal of Forestry and Horticulture (IJFH), vol. 5, no. 4, pp. 10-21, 2019. Available: DOI: http://dx.doi.org/ 10.20431/2454-9428.0504002

Copyright: (C) 2019 Authors. This is an open-access article distributed under the terms of the Creative Commons Attribution License, which permits unrestricted use, distribution, and reproduction in any medium, provided the original author and source are credited. 